University of Nebraska - Lincoln

DigitalCommons@University of Nebraska - Lincoln

Nebraska Cooperative Fish \& Wildlife Research Nebraska Cooperative Fish \& Wildlife Research Unit -- Staff Publications

2008

\title{
Power laws, discontinuities and regional city size distributions
}

\author{
Ahjond S. Garmestani \\ Clemson University, garmestani.ahjond@epa.gov \\ Craig R. Allen \\ University of Nebraska-Lincoln, callen3@unl.edu \\ Colin M. Gallagher \\ Clemson University
}

Follow this and additional works at: https://digitalcommons.unl.edu/ncfwrustaff

Part of the Other Environmental Sciences Commons

Garmestani, Ahjond S.; Allen, Craig R.; and Gallagher, Colin M., "Power laws, discontinuities and regional city size distributions" (2008). Nebraska Cooperative Fish \& Wildlife Research Unit -- Staff Publications. 28.

https://digitalcommons.unl.edu/ncfwrustaff/28

This Article is brought to you for free and open access by the Nebraska Cooperative Fish \& Wildlife Research Unit at DigitalCommons@University of Nebraska - Lincoln. It has been accepted for inclusion in Nebraska Cooperative Fish \& Wildlife Research Unit -- Staff Publications by an authorized administrator of DigitalCommons@University of Nebraska - Lincoln. 


\title{
Power laws, discontinuities and regional city size distributions
}

\author{
Ahjond S. Garmestani ${ }^{\mathrm{a}, *}$, Craig R. Allen ${ }^{\mathrm{b}}$, Colin M. Gallagher ${ }^{\mathrm{c}}$ \\ a South Carolina Cooperative Fish and Wildlife Research Unit and Program in Policy Studies, Clemson University, \\ Clemson, SC 29634, USA \\ ${ }^{\mathrm{b}}$ USGS-Nebraska Cooperative Fish and Wildlife Research Unit, University of Nebraska, Lincoln, NE 68583-0711, USA \\ ${ }^{\mathrm{c}}$ Department of Mathematics, Clemson University, Clemson, SC 29634, USA \\ Received 11 April 2006; received in revised form 24 March 2008; accepted 25 March 2008 \\ Available online 11 April 2008
}

\begin{abstract}
Urban systems are manifestations of human adaptation to the natural environment. City size distributions are the expression of hierarchical processes acting upon urban systems. In this paper, we test the entire city size distributions for the southeastern and southwestern United States (1990), as well as the size classes in these regions for power law behavior. We interpret the differences in the size of the regional city size distributions as the manifestation of variable growth dynamics dependent upon city size. Size classes in the city size distributions are snapshots of stable states within urban systems in flux.
\end{abstract}

(C) 2008 Published by Elsevier B.V.

Keywords: City size distributions; Power laws; Discontinuities; Complex systems

\section{Introduction}

Cities are the product of economies of scale in production. Without scale economies, cities would not have to exist because economic activities would be dispersed to reduce transportation costs (Quigley, 1998). Urban economic analysis has suggested that the size of a city is dependent upon a complex mix of factors, including human capital and specialized inputs (Wheeler, 2003). These factors can create a positive feedback loop that acts as an attractor to further growth. Urban theory predicts that at a threshold size, agglomeration benefits decrease and diseconomies (e.g., crime, congestion, living expenses, etc.) increase; cities should grow to a certain point, and then growth rates should decrease as size increases (Wheeler, 2003). There is evidence of this phenomenon, as larger cities tend to grow at a slower pace (Dobkins and Ioannides, 2001), which may be indicative of cities growing faster when their market potential is large relative to their size, but that growth slows as a city's size nears a critical threshold (Duranton and Puga, 2000). Capello and Camagni (2000) assert that economies of scale are not a factor above a certain threshold city size. Beyond that threshold, they claim that higher urban functions and interaction with other cities take precedence as variables in explaining city size. Further, the concentration of population into cities allows not only for social interaction and economic efficiency, but also for increasing returns on the use of non-renewable resources (Capello and Camagni).

Tabuchi et al. (2005) developed a model of city growth and replication and found that growth rates are variable with respect to size, number of cities, and transportation costs. Sharma (2003) found that cities in India had periods

\footnotetext{
* Corresponding author.

E-mail addresses: agarmes@clemson.edu (A.S.Garmestani), allencr@unl.edu (C.R. Allen), CGALLAG@CLEMSON.EDU (C.M. Gallagher).
} 
of size-independent growth as well as periods of size-dependent growth. Garmestani et al. (2007) found that regional city size distributions in the U.S. exhibited size-dependent growth rates. Utilizing time series data, they found that smaller cities grow faster than average, and larger cities grow slower than average. Cities grow faster when they are small relative to their market potential, implying non-random growth rates for cities (Ioannides and Overman, 2004).

Anderson and $\mathrm{Ge}$ (2005) reported that Chinese cities were characterized by size-invariant growth up to the economic reform period of 1979 that triggered a convergence of city growth. They found that small cities grew faster than larger cities after the reform period in China, which demonstrates that Chinese city size distributions differ significantly from Zipf's and Gibrat's law. City growth provides insight about shifts in production patterns, income distribution, and economic growth (Sharma, 2003). Sharma suggests that cities exhibit a long-term growth rate, but that rate can be altered via exogenous shocks that alter the growth trajectory in the short-term. City size is a path dependent process, as a city's present size is strongly influenced by its past size (Sharma). Congestion, overcrowding, and declining opportunities begin to have an effect on city growth, so that growth begins to slow in large cities (Sharma). In this context, Bessey (2002) suggested that functional processes act as corollaries of the "slaving principle" in which large-scale, slow processes (e.g., national economies) enslave small-scale, fast processes (e.g., regional and city economies).

Power laws are a useful tool in studying complex systems because scaling relations may indicate that the system is controlled by a few rules that propagate across a wide range of scales (Meakin, 1993; Stanley et al., 1996). Urban distributions have been described by Zipf's law or the rank-size rule (Zipf, 1949). Zipf's law predicts that city size distributions will have a continuous distribution and conform to the restraints of a linear power law (Gabaix, 1999). Thus, the assumption is that city sizes of a certain range will have similar growth processes (Gibrat's law) regardless of the particulars driving the growth of cities, and that the distribution of these cities will conform to Zipf's law (Gibrat, 1957; Gabaix, 1999). Bessey has found that bi- and poly-modality are defining features of U.S. urban systems at national and regional scales. Bessey utilized rank-size and constant-Gini models to analyze national and regional city size data. These models revealed that there were departures from the Zipf prediction for the data in this manuscript and increasing population concentration in the largest cities (i.e., upper tail of the city size distribution) in each region.

This analysis builds upon Bessey, who identified departures from Zipf's Law for cities in the southeastern and southwestern regions of the U.S. Utilizing this same data, Garmestani et al. (2007) found departures from Gibrat's law, in that city growth is correlated to size, with smaller cities exhibiting faster growth rates and larger cities exhibiting slower growth rates. In addition, Garmestani et al. (2008) analyzed this data and found that cities in the southeastern U.S. self-organize into discrete size classes, much as they were found to do in the southwestern U.S. (Garmestani et al., 2005). In this paper, we test the entire city size distributions for the southeastern and southwestern U.S. (1990), as well as the individual size classes previously identified in Garmestani et al. (2008) for power law behavior.

\section{Methods}

We define a city as a human settlement above a threshold population size that satisfies the functional requirements of that population (Bessey). The cutoff for determining what is urban is arbitrary and arises from practical rather than theoretical considerations (Marshall, 1989). This analysis used a U.S. Census dataset incorporating the urbanized area (UA) definition. A UA comprises a central place and the urban fringe, which includes other "places" (Bessey, 2000). The Bureau of the Census officially defines a "place" as a concentration of population that must have a name and be locally recognized, although it may or may not be legally incorporated under the laws of its state (Bessey, 2002).

Many Bureau of the Census classifications have evolved over the last 120 years. Regional systems theory conceives of cities as the central places in regional, social, and economic systems, nested within a larger hierarchy of cities and regions (Skinner and Henderson). U.S. urban development in the 20th century was characterized by sharp regional patterns (Overman and Ioannides, 2001). Bureau of Economic Analysis (BEA) regions comprise defined entities whose boundaries hold historically. Additionally, aggregating cities on a national scale masks discontinuous patterns that manifest at a regional scale (Skinner and Henderson, 1999). Functional economic regions likely capture scale effects better than convenient political divisions (Rigby and Essletzbichler, 2002). Analyzing the data based on BEA regions allowed for research along smaller and more uniform biophysical, economic, and socio-cultural characteristics (Bessey).

We ranked cities in order of population size to determine whether size classes existed within the city size distribution. This study used a BEA dataset of cities in the southeastern (Alabama, Arkansas, Florida, Georgia, Kentucky, Louisiana, Mississippi, North Carolina, South Carolina, Tennessee, Virginia, and West Virginia) and southwestern (Arizona, New 
Mexico, Oklahoma, and Texas) regions of the United States. City size distributions were analyzed with simulations that compared actual data with a null distribution established by calculating a kernel density estimate of the log-transformed data (Hall and York, 2001). Significance of size classes in the data was determined by calculating the probability that the observed discontinuities were chance events by comparing observed values with the output of 1000 simulations from the null set (Restrepo et al., 1997). Because $n$ in our datasets was 310 cities (SE, 1990) and 161 cities (SW, 1990), we maintained a constant statistical power of $\sim 0.50$ for detecting discontinuities (Lipsey, 1990). Maintaining constant power rather than constant alpha levels (i.e., keeping Type II error rates constant rather than Type I error rates) is a more robust approach when the focus is the detection and comparison of pattern (Holling and Allen, 2002). We confirmed our results with hierarchical cluster analysis based on variance reduction (SAS Institute, 1999). A discontinuity was defined as an area between successive city sizes that significantly exceeded the differences between adjacent city sizes generated by the continuous null distribution (Allen et al., 1999). A size class was a grouping of three or more cities with populations not exceeding the expectation of the null distribution (Allen et al.). City size classes were defined by the two end-point cities that defined either the upper or the lower extremes of the size class (Allen et al.).

In order to help to visualize the dynamics of the city size distribution, linear regression models relating log rank to $\log$ city size were fit: one for the overall dataset, and one for each identified size class. The slope of each regression line is a rough estimate of the rate of change of the right tail of the city size distribution $P(X>t)$. More specifically, if one approximates $P(X>t) \approx t^{-1 / \alpha}$, the regression slope is an estimate of $-\alpha$. A note of caution is that although the $p$-values for significance tests for the regression slope provide some indication of the fit to the data, these $p$-values cannot be used to perform a formal hypothesis test. This is because the data consist of ordered values of the logarithm of city size that are not independent, meaning the standard regression assumptions are not met. However, the coefficient of determination, $r^{2}$, maintains its usual interpretation; namely, this measures the proportion of the variation in the ordered log city sizes explained by the regression line.

\section{Results}

There were 310 cities in the southeastern U.S. that self-organized into 3 discrete size classes. A power law can be fit to the overall rank-size city data $\left(r^{2}=0.9693\right.$; Fig. 1), but results in a poor fit for the upper tail of the distribution. Power laws provide good fits for each of the individual size classes (Fig. 2). The three size classes were differentiated by different slopes and intercepts. The first group of 14 cities resulted in a least squares line that explains $r^{2}=0.9524$ of the variation in the $14 \mathrm{log}$ city sizes and had an estimated slope of -0.24065 with an associated standard error of 0.01553 . The second group consisting of 30 cities had a fitted line explaining $97.59 \%$ of the variation in those log city sizes. The slope for this group is -0.36923 with a standard error of 0.01096 . The regression line for the final group of 266 cities explained $97.97 \%$ of the variation in log city size and had an estimated slope of -0.642944 with a standard error of 0.005703 . While we cannot apply a standard statistical test, the slope for the second group is more than 8

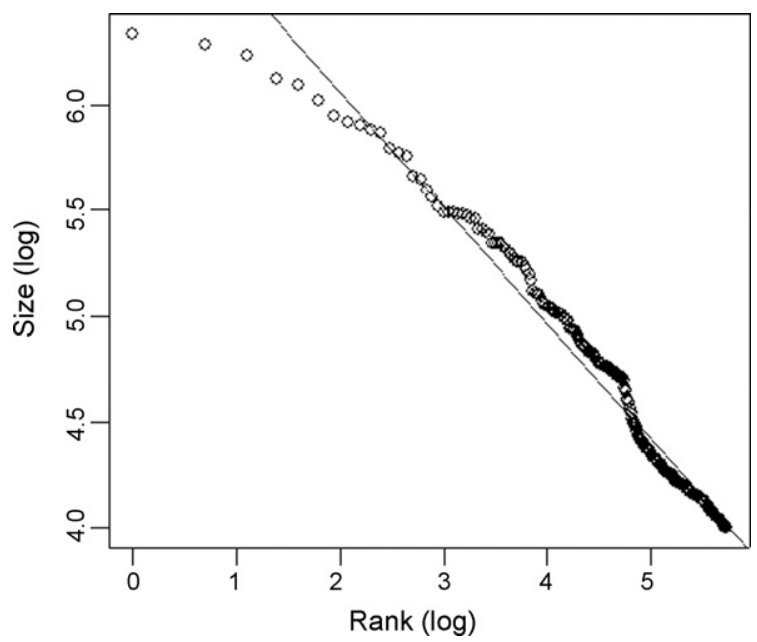

Fig. 1. Rank-size (log) city distribution for the southeastern U.S. (1990) with a power law fitting the entire distribution. 


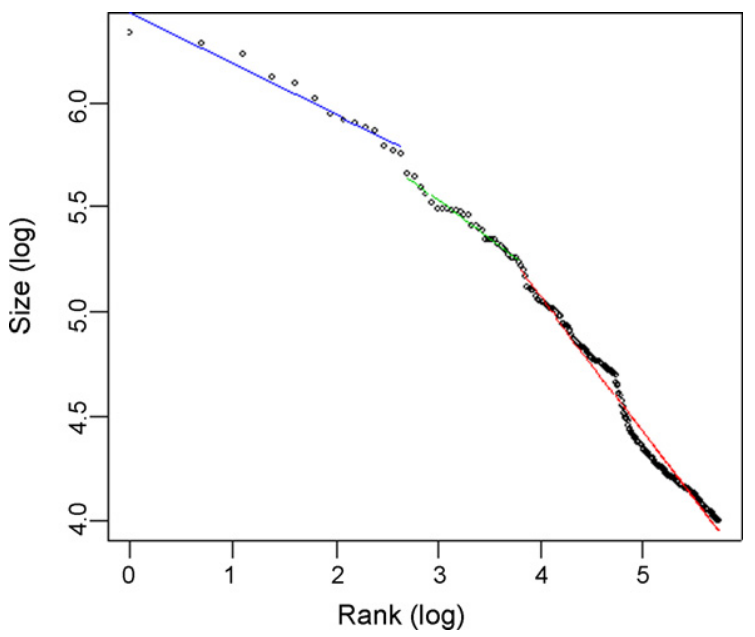

Fig. 2. Rank-size (log) city distribution for the southeastern U.S. (1990). Power laws are fitted to each of the individual size classes in the distribution.

standard errors away from the estimate for the second group. Also, the estimated slope for the third group is more than 25 standard errors away from the estimated slope for the second group. Thus, it seems reasonable to conclude there is a statistically significant difference between the three slopes.

There were 161 cities in the southwestern U.S., which self-organized into 6 discrete size classes. A power law provides a good fit for the overall rank-size city data $\left(r^{2}=0.9903\right.$; Fig. 3). Power laws provide good fits for each of the individual size classes (Fig. 4). The six size classes were differentiated by different slopes and intercepts. The first group of 5 cities resulted in a least squares line that explains $r^{2}=0.8264$ of the variation in the $5 \log$ city sizes and had an estimated slope of -0.8683 with an associated standard error of 0.2297 . The second group consisting of 5 cities had a fitted line explaining $r^{2}=0.8399$ of the variation in those log city sizes. The slope for this group is -0.41045 with a standard error of 0.10348 . The regression line for the third group of 3 cities explained $r^{2}=0.7831$ of the variation in $\log$ city size with an estimated slope of -2.143 with a standard error of 0.1128 . The fourth group consisting of 27 cities had a fitted line explaining $r^{2}=0.9773$ of the variation in those log city sizes. The slope for this group is -0.95794 with a standard error of 0.02861 . The fifth group consisting of 3 cities had a fitted line explaining $r^{2}=0.7521$ of the variation in those $\log$ city sizes. The slope for this group is -0.5753 with a standard error of 0.3303 . The sixth group consisting of 116 cities had a fitted line explaining $r^{2}=0.9966$ of the variation in those log city sizes. The slope for this group is -1.030415 with a standard error of 0.005622 .

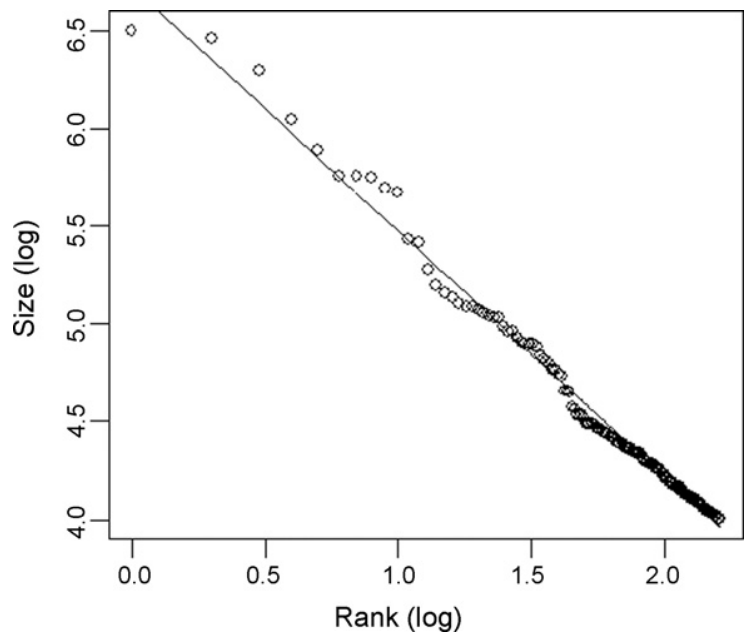

Fig. 3. Rank-size (log) city distribution for the southwestern U.S. (1990) with a power law fitting the entire distribution. 


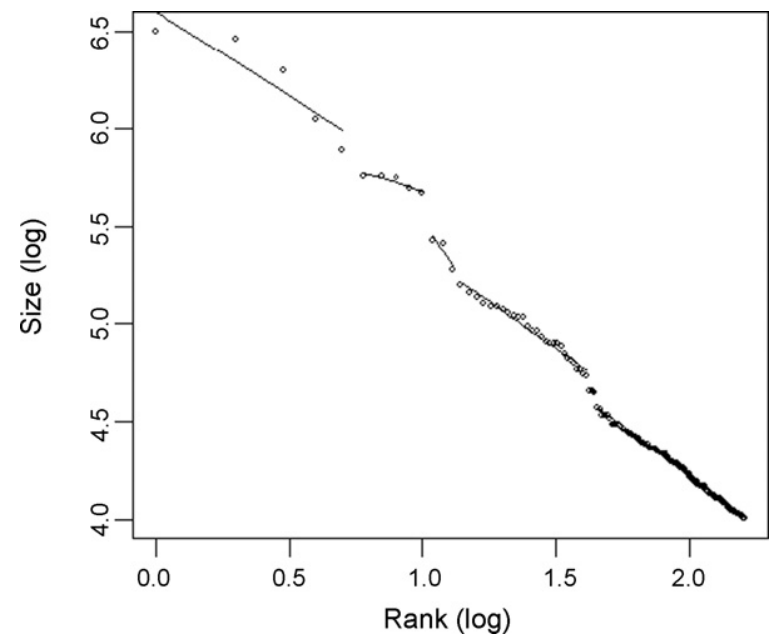

Fig. 4. Rank-size (log) city distribution for the southwestern U.S. (1990). Power laws are fitted to each of the individual size classes in the distribution.

\section{Discussion}

Power laws provide fits for the overall city size distribution for the southeastern and southwestern regions (1990) of the U.S. Cities in the southeastern region self-organized into three discrete size classes, and the southwestern region was self-organized into six size classes, each of which is also well described by power laws with differing slopes and intercepts. With respect to the different power law fits for the individual size classes, the overall power law for a distribution does not capture evidence of the processes affecting city size at a finer scale of analysis (i.e., the individual size classes). The southeastern region has a longer urban developmental history than the southwestern region of the U.S. Thus, the southeastern region is representative of a more mature system, one in which growth dynamics have created more stability within the system. As for the southwestern region, the greater variability in the power law fits for the individual size classes indicates that the system is one in flux. Different power law fits for individual size classes support the proposition that different processes (e.g., growth rates) act upon cities at different scales. We interpret the differences in the power law fits in the city size distributions as the manifestation of variable growth dynamics dependent upon city size. Additionally, these results clearly demonstrate that power law and discontinuity characterizations of variables in complex systems are not mutually exclusive, but rather complementary.

Cities grow faster when they are small relative to their market potential, implying non-random growth rates for cities (Ioannides and Overman). The spatial interaction and previous development of a site play a critical role in the future growth trajectory of a site (Ioannides and Overman). Fujita et al. (1999) predicted that discontinuities in the landscape strengthen the role of cities' agglomeration shadows and that the nonlinear interactions in an urban system spur asymmetric behavior when new cities emerge. The agglomeration shadow of existing cities implies that the earlier a site has been settled, the more likely the city will grow (Ioannides and Overman). Duranton (2002) views small, innovation-driven technology shocks as the main driver behind city growth rates. In this model, cities grow or decline as they gain or lose industries following new innovations (Duranton). Examples of this phenomenon are the decline of the steel industry in Pittsburgh and the rise of internet-related industries in Silicon Valley (Duranton). Economic activity in the U.S. is highly concentrated (Wheeler, 2001). County-level research has indicated that growth rates are correlated up to 40 miles, which suggests a strong agglomeration effect to economic concentration (Wheeler, 2001).

Zipf's law is believed to be a reflection of a steady state condition (Bessey). Thus, the assumption is that cities and firms will have similar growth rates regardless of the processes driving growth (Gibrat). This "law" assumes that growth is independent of size. Importantly, Zipf's is predicated by Gibrat's law (Gabaix). The majority of research conducted upon Gibrat's law has been undertaken utilizing firm data. Several studies on firm size have shown that Gibrat's law fails to hold (Kumar, 1985; Evans, 1987; Hall, 1987; Dunne et al., 1989). Evans found a negative relationship between firm growth and size, and a negative relationship between firm growth and the age of the firm. Almus and Nerlinger (2000) reported that growth rates were higher for smaller firms and that innovative young firms had higher average 
growth rates than non-innovative firms. They assert that small firms have a higher growth rate because they must reach a minimum economy of scale level of output in order to increase their chances of survival (Simon and Bonini, 1958; Almus and Nerlinger, 2000). Rossi-Hansberg and Wright (2007) developed a general equilibrium theory of economic growth that produced a city size distribution captured by Zipf's law, but with departures in the tails of the distribution. They assert that the deviations in Zipf's law are attributable in part, to size-dependent growth rates (Rossi-Hansberg and Wright, 2007), a conclusion supported by Garmestani et al. (2007). In a study of city size distributions for the years 1957, 1970, 1980, 1991 and 2000 in Malaysia, Soo (2007) found that Zipf's law was rejected for all periods except 1957. In addition, evidence contrary to Gibrat's law was also found, which serves as a partial explanation for the observed departures from Zipf's law (Soo). These departures from Gibrat's law demonstrate, in some cases, that growth is size-dependent (Klette and Griliches, 2000; Garmestani et al., 2007).

Size is a critical factor for manufacturing firms (Mittelstaedt et al., 2003). Manufacturing firms in South Carolina must reach a critical size ( $>20$ employees) before they can engage in import-export operations. Within the economic literature on firm size and growth rates for developing countries, there is evidence that larger firms grow slower than smaller firms (Sleuwaegen and Goedhuys, 2002; Van Biesbroeck, 2005). Van Biesebroeck found that large firms remain large in Africa, allowing for little change in the hierarchy of the continent. This suggests that smaller, less productive firms have a difficult time reaching the threshold necessary for a transition to a size that allows them to persist. In short, size matters.

Cross-country growth exhibits behavior that is best characterized via convergence clubs, in which the economy of the country is auto-correlated with other countries with similar growth, resulting in multiple steady states (Durlauf and Johnson, 1995). Similar to the dynamics of convergence clubs, the interaction between endogenous comparative advantages and exogenous trade and transportation patterns trigger discontinuities in city growth rates, which manifest in cities clustering into distinct size classes (Dendrinos and Rosser, 1992). Economic growth can manifest multiple stable steady states (i.e., convergence clubs) via differential growth rates (Durlauf, 1996). Assuming that complex systems are evolving to a single steady state, as opposed to systems characterized by multiple steady states, can lead to collapse in ecosystems (Peterson et al., 2003) and economic systems (Brock and Hommes, 1997).

\section{Conclusion}

Endogenous economic growth depends upon infrastructure investment that likely lowers transportation costs, increasing the degree of linkage among agents (Rosser, 2003). Researchers have found evidence for increased structural and dynamic complexity at the edge of chaos in simple, discrete models (Kauffman and Johnsen, 1991; Langton, 1990). Kauffman (1993) has suggested that systems poised at a critical transition are highly adaptable, which could manifest in abrupt change. The interaction between fast and slow variables in an economy is characterized by increasing instability, which leads to fluctuations caused by those instabilities triggering abrupt change above a critical threshold (Brock and Hommes). Discontinuities can arise endogenously in dynamic systems in the presence of dynamic instabilities in the system (Rosser, 2000). Rosser (2003) states that the organization of an economic system is dependent upon the linkage between agents, which changes discontinuously via critical transitions at this linkage. Beyond this bifurcation point, a greater degree of regional linkage heightens volatility as agents drive the system towards divergent growth trajectories (Rosser, 2003).

New hierarchical levels can emerge in urban systems via an expansion of trade, lower transportation costs, or change in the internal structures of cities (Rosser, 1994). Nonlinear oscillations can trigger a phase transition and the emergence of a new level in a hierarchy. An emergent level is evidence of discontinuity in the organization of a system (Goldstein, 2002). This new level of organization is a construct of the adaptive cycle in systems, which manifests in marked change between levels of a hierarchy.

These discontinuities, or gaps, between size classes may be indicative of thresholds, where the scaling laws applicable to larger or smaller cities do not apply (Peterson et al., 1998; Allen et al., 1999). The range of possible movements within a stable state that can occur without generating a bifurcation is the domain of attraction (Ludwig et al., 2002). Holling et al. (2002) suggest that agglomeration forces (e.g., attractors) entrain cities with similar growth rates into size classes, similar to species in an ecosystem. Complex systems can manifest multiple stable states (Gunderson et al., 2002), and we assert that these size classes are evidence of multiple stable states within a system and that the power law fits for each size class are indicative of discrete ranges of scale at which cities are governed by similar processes. 


\section{Acknowledgements}

Support was provided by the James S. McDonnell Foundation 21st Century Research Award/Studying Complex Systems. The South Carolina Cooperative Fish and Wildlife Research Unit is jointly supported by a cooperative agreement between the United States Geological Survey, the United States Fish and Wildlife Service, the South Carolina Department of Natural Resources, Clemson University, and the Wildlife Management Institute. The Nebraska Cooperative Fish and Wildlife Research Unit is jointly supported by a cooperative agreement between the United States Geological Survey, the Nebraska Game and Parks Commission, the University of Nebraska-Lincoln, the United States Fish and Wildlife Service and the Wildlife Management Institute. This manuscript was improved by comments from A.T. Karunanithi. This research is dedicated to the memory of K.M. Bessey.

\section{References}

Allen, C.R., Forys, E.A., Holling, C.S., 1999. Body mass patterns predict invasions and extinctions in transforming landscapes. Ecosystems 2 , $114-121$.

Almus, M., Nerlinger, E.A., 2000. Testing "Gibrat's Law" for young firms—empirical results for West Germany. Small Business Economics 15, $1-12$.

Anderson, G., Ge, Y., 2005. The size distribution of Chinese cities. Regional Science and Urban Economics 35, 756-776.

Bessey, K.M., 2000. Scale, structure and dynamics in the U.S. urban systems, 1850-1990: city size in the lens of region. Ph.D. Thesis, Harvard University, Cambridge, MA.

Bessey, K.M., 2002. Structure and dynamics in an urban landscape: toward a multiscale view. Ecosystems 5, 360-375.

Brock, W.A., Hommes, C.A., 1997. A rational route to randomness. Econometrica 65, 1059-1095.

Capello, R., Camagni, R., 2000. Beyond optimal city size: an evaluation of alternative urban growth patterns. Urban Studies 37, $1479-1496$.

Dendrinos, D.S., Rosser, J.B., 1992. Fundamental issues in nonlinear urban population dynamic models: theory and a synthesis. Annals of Regional Science 26, 135-145.

Dobkins, L.H., Ioannides, Y.M., 2001. Spatial interactions among U.S. cities: 1900-1990. Regional Science and Urban Economics 31, 701-731.

Dunne, T., Roberts, M.J., Samuelson, L., 1989. The growth and failure of U.S. manufacturing plants. The Quarterly Journal of Economics 104, 671-698.

Duranton, G., 2002. City size distributions as a consequence of the growth process. CEPR Discussion Paper No. 3577. Available at SSRN: http://ssrn.com/abstract=348580.

Duranton, G., Puga, D., 2000. Diversity and specialization in cities: why, where and when does it matter? Urban Studies 37, 533-555.

Durlauf, S.N., 1996. On the convergence and divergence of growth rates. The Economic Journal 106, 1016-1018.

Durlauf, S.N., Johnson, P.A., 1995. Multiple regimes and cross-country growth behaviour. Journal of Applied Econometrics 10, $365-384$.

Evans, D., 1987. The relationship between firm growth, size and age: estimates for 100 manufacturing industries. Journal of Industrial Economics $35,567-581$.

Fujita, M., Krugman, P., Venables, A., 1999. The Spatial Economy. MIT Press, Cambridge, MA.

Gabaix, X., 1999. Zipf's law for cities: an explanation. Quarterly Journal of Economics 3, 739-767.

Garmestani, A.S., Allen, C.R., Bessey, K.M., 2005. Time series analysis of clusters in city size distributions. Urban Studies 42, $1507-1515$.

Garmestani, A.S., Allen, C.R., Gallagher, C.M., Mittelstaedt, J.D., 2007. Departures from Gibrat's Law, discontinuities and city size distributions. Urban Studies 44, 1997-2007.

Garmestani, A.S., C.R. Allen and K.M. Bessey. 2008. Discontinuities in urban systems: comparison of regional city-size structure in the United States. In: C.R. Allen and C.S. Holling (eds.), Discontinuities in ecosystems and other complex systems, Columbia University Press. 288pp.

Gibrat, R., 1957. On economic inequalities. International Economic Papers 7, 53-70.

Goldstein, J., 2002. The singular nature of emergent levels: suggestions for a theory of emergence. Nonlinear Dynamics, Psychology, and Life Sciences 6, 293-309.

Gunderson, L.H., Pritchard Jr., L., Holling, C.S., Folke, C., Peterson, G.D., 2002. A summary and synthesis of resilience in large-scale systems. In: Gunderson, L.H., Pritchard Jr., L. (Eds.), Resilience and the Behavior of Large-Scale Systems. Island Press, Washington, D.C., pp. $249-261$.

Hall, B., 1987. The relationship between firm size and firm growth in the U.S. manufacturing sector. Journal of Industrial Economics 35, 583-606.

Hall, P., York, M., 2001. On the calibration of Silverman's test for multimodality. Statistica Sinica 11, 515-536.

Holling, C.S., Allen, C.R., 2002. Adaptive inference for distinguishing credible from incredible patterns in nature. Ecosystems 5, 319-328.

Holling, C.S., Gunderson, L.H., Peterson, G.D., 2002. Sustainability and panarchies. In: Gunderson, L.H., Pritchard Jr., L. (Eds.), Resilience and the Behavior of Large-Scale Systems. Island Press, Washington, D.C., pp. 63-102.

Ioannides, Y.M., Overman, H.G., 2004. Spatial evolution of the U.S. urban system. Journal of Economic Geography 4, 1-26.

Kauffman, S.A., 1993. The Origins of Order: Self-Organization and Selection in Evolution. Oxford University Press, Oxford.

Kauffman, S.A., Johnsen, S., 1991. Coevolution to the edge of chaos: coupled fitness landscapes, poised states, and coevolutionary avalanches. Journal of Theoretical Biology 149, 467-505.

Klette, J., Griliches, Z., 2000. Empirical patterns of firm growth and R\&D investment: a quality ladder model interpretation. The Economic Journal $110,363-387$.

Kumar, M.S., 1985. Growth, acquisition activity and firm size: evidence from the United Kingdom. Journal of Industrial Economics 33, 327-338. 
Langton, C.G., 1990. Computation at the edge of chaos: phase transitions and emergent computation. Physica D 42, $12-37$.

Lipsey, M.W., 1990. Design sensitivity: statistical power for experimental research. Sage Publications, London.

Ludwig, D., Walker, B.H., Holling, C.S., 2002. Models and metaphors of sustainability, stability, and resilience. In: Gunderson, L.H., Pritchard Jr.,

L. (Eds.), Resilience and the Behavior of Large-Scale Systems. Island Press, Washington, D.C., pp. 21-48.

Marshall, J.U., 1989. The Structure Of Urban Systems. University of Toronto Press, Toronto.

Meakin, P., 1993. The growth of rough surfaces and interfaces. Physical Letters 235, 189-289.

Mittelstaedt, J.D., Harben, G.N., Ward, W.A., 2003. How small is too small? Firm size as a barrier to exporting from the United States. Journal of Small Business Management 41, 68-84.

Overman, H.G., Ioannides, Y.M., 2001. Cross-sectional evolution of the U.S. city size distribution. Journal of Urban Economics 49, 543-566.

Peterson, G.D., Allen, C.R., Holling, C.S., 1998. Ecological resilience, biodiversity and scale. Ecosystems 1, 6-18.

Peterson, G.D., Carpenter, S.R., Brock, W.A., 2003. Uncertainty and the management of multistate ecosystems: an apparently rational route to collapse. Ecology 84, 1403-1411.

Quigley, J.M., 1998. Urban diversity and economic growth. The Journal of Economic Perspectives 12, 127-138.

Restrepo, C., Renjifo, L.M., Marples, P., 1997. Frugivorous birds in fragmented neotropical montane forests: landscape pattern and body mass distribution. In: Laurance, W.F., Bierregaard, R.O. (Eds.), Tropical Forest Remnants: Ecology, Management and Conservation of Fragmented Communities. University of Chicago Press, Chicago, pp. 171-189.

Rigby, D.L., Essletzbichler, J., 2002. Agglomeration economies and productivity differences in U.S. cities. Journal of Economic Geography 2, 407-432.

Rosser, J.B., 1994. Dynamics of emergent urban hierarchy. Chaos, Solitons, and Fractals 4, 553-561.

Rosser, J.B., 2000. A new perspective on economic discontinuity. Journal of Management and Economics 4, 4.

Rosser, J.B., 2003. A reconsideration of the role of discontinuity in regional economic models. Chaos, Solitons and Fractals 18, 451-462.

Rossi-Hansberg, E., Wright, M.L.J., 2007. Urban structure and growth. Review of Economic Studies 74, 597-624.

SAS Institute Inc., 1999. SAS User's Guide: Statistics, Version 5. SAS Institute, Cary, North Carolina.

Sharma, S., 2003. Persistence and stability in city growth. Journal of Urban Economics 53, 300-320.

Skinner, G.W., Henderson, M., 1999. Analyzing the urban hierarchy. In: Proceedings of Geoinformatics and Socioinformatics, Berkeley, California: Association of Chinese Professionals in Geographic Information Systems.

Sleuwaegen, L., Goedhuys, M., 2002. Growth of firms in developing countries, evidence from Cote d'Ivoire. Journal of Development Economics $68,117-135$.

Simon, H.A., Bonini, C.P., 1958. The size distribution of business firms. American Economic Review 58, 607-617.

Soo, K.T., 2007. Zipf's law and urban growth in Malaysia. Urban Studies 44, 1-14.

Stanley, H.E., Amaral, L.A.N., Buldyrev, S.V., Goldberger, A.L., Havlin, S., Leschhorn, H., Maass, P., Makse, H.A., Peng, C.-K., Salinger, M.A., Stanley, M.H.R., Viswanathan, G.M., 1996. Scaling and universality in animate and inanimate systems. Physica A 231, 20-48.

Tabuchi, T., Thisse, J.-F., Zeng, D.-Z., 2005. On the number and size of cities. Journal of Economic Geography 5, $423-448$.

Van Biesbroeck, J., 2005. Firm size matters: growth and productivity growth in African manufacturing. Economic Development and Cultural Change $53,545-583$.

Wheeler, C.H., 2001. A note on the spatial correlation structure of county-level growth in the U.S. Journal of Regional Science 41, $433-449$.

Wheeler, C.H., 2003. Evidence on agglomeration economies, diseconomies, and growth. Journal of Applied Econometrics 18, 79-104.

Zipf, G.K., 1949. Human Behaviour and the Principle of Least Effort: An Introduction to Human Ecology. Addison-Wesley, Cambridge, MA. 